\title{
TÉCNICO E CIDADÃO, EIS A QUESTÃO: UM CASO DE PARTICIPAÇÃO PÚBLICA NO ESPAÇO URBANO
}

\author{
Paula Castro $^{1}$ \\ Susana Batel ${ }^{2}$
}

Resumo: Neste trabalho pretendemos examinar uma controvérsia relativa ao património construído das cidades e à participação do público, que envolveu os sistemas técnico e leigo. Trata-se da controvérsia relativa ao Convento dos Inglesinhos, um conjunto patrimonial do século XVII que ocupa um quarteirão do Bairro Alto, um dos bairros mais emblemáticos de Lisboa, e para o qual está actualmente prevista a transformação num condomínio residencial fechado de luxo. O projecto, aprovado pelos técnicos camarários sem consulta pública aos moradores, provocou um debate público intenso quando um movimento de moradores do Bairro organizou protestos e debates públicos contra a transformação. Neste trabalho, reconstruímos primeiro o contexto representacional desta controvérsia, baseando-nos na análise das notícias da imprensa, na nossa participação nas sessões públicas organizadas pelos moradores e nas entrevistas realizadas com os principais protagonistas, análises que permitiram compreender as representações sobre a cidade, o património e o papel dos cidadãos, aqui envolvidos. Analisamos mais detalhadamente as entrevistas narrativas realizadas aos técnicos camarários, que permitiram examinar como é que os técnicos gerem o dilema de não poderem falar abertamente contra a participação pública - com legitimidade normativa nas sociedades actuais -, ao mesmo tempo que resistem aos objectivos dos moradores, reiterando as suas próprias decisões. Recorrendo à noção de polifasia cognitiva, analisamos as contradições que daqui emergem e como se relacionam com as diferentes identidades que os técnicos podem assumir - técnico e cidadão. Discutimos ainda como é que a gestão deste dilema e o recurso à contradição podem contribuir para impedir que os cidadãos participem por uma via legal, fomentando maior anomia quanto aos problemas dos espaços construídos.

Palavras-chave: participação pública, representações sociais, esfera pública, polifasia cognitiva.

Technician and citizen, that is the question: A case of public participation in an urban setting (Abstract): In this paper we analyse how the technical and lay systems engage in public debate, examining a case of public participation concerning the

\footnotetext{
${ }^{1}$ Departamento de Psicologia Social e das Organizações, ISCTE.

${ }^{2}$ Departamento de Psicologia Social e das Organizações, ISCTE.

PSICOLOGIA, Vol. XXI (2), 2007, Edições Colibri, Lisboa, pp. 99-117.
} 
built heritage. This case concerns the transformation of a XVII Convent - Convento dos Inglesinhos - located in the Bairro Alto, into a closed residential condominium for the affluent. This project was accepted by the Town Hall technicians without public consultation, and gave rise to several protests and debate sessions. In this article, we first sketch the representational field of the controversy, through the analysis of the press, our notes form the public sessions organised by the dwellers and the interviews with the main actors. Afterwards we examine the interviews with the Town Hall technicians in a more detailed manner, showing that they look at this controversy from two different identities: citizen and technician. When they step in the citizen's shoes, they argue in favour of citizenship rights and public participation as one of them, but when assuming their identities as technicians of the Gabinete do Bairro Alto, they oppose this particular public movement, particularizing it as not participation and dismissing the dwellers goals. The notion of Cognitive polyphasia is used to examine how they manage this double positioning and how this is related to their different identities. We also discuss how the management of this dilemma and the use of contradiction may prevent citizens from participating through a legal way in the decisions that affect their communities, and how this may promote anomic behaviours concerning the problems of the urban spaces.

Key-words: public participation, social representations, public sphere, cognitive polyphasia.

\section{Introdução}

Em Agosto de 2004, chega à primeira página de um jornal diário da capital portuguesa a notícia do estalar de uma controvérsia relativa à demolição do denominado Convento dos Inglesinhos, conjunto patrimonial do século XVII constituído por Convento, Colégio, Igreja e jardim, situado no centro do Bairro Alto, e sua subsequente substituição por um condomínio residencial de luxo, de acordo com o projecto de um grupo privado. Vendido em 1984 à Santa Casa da Misericórdia de Lisboa, pelos seus próprietários originais, uma congregação católica inglesa, para ser transformado num complexo residencial de luxo para a terceira idade, o Convento ficou desde aí sem qualquer tipo de intervenção ou uso. Em 2000, a Misericórdia vende o Convento a um grupo imobiliário privado sem que a Câmara Municipal de Lisboa exerça o seu direito de preferência. Porém, o grupo acaba por abandonar a ideia de construir uma residência para a terceira idade, optando por construir um condomínio fechado de luxo para habitação. É quando começa a ser publicitada a venda dos apartamentos deste condomínio que começa a tomar forma um protesto protagonizado por um grupo de moradores do Bairro. Este grupo insurge-se contra a obra, a deliberação da CML que permitira a venda do imóvel e o projecto arquitectónico, o qual inclui a 
transformação do Convento em apartamentos, a transformação de algumas partes da Igreja e a eliminação do jardim. Para além de organizar sessões públicas para esclarecimento dos seus objectivos e estruturação da sua acção, este grupo de moradores procurou discutir esta questão com os responsáveis da CML e avançou com uma providência cautelar para impedir a transformação. Desta forma, a controvérsia que então se iniciou opôs este grupo de moradores, quer ao proprietário da obra, quer aos técnicos do Gabinete local da Câmara, que haviam aprovado o projecto sem consulta pública.

Esta controvérsia foi por nós tomada como uma oportunidade para tentar compreender que forma tomam, na esfera pública, os debates entre os sistemas técnico e leigo relativos a questões de desenvolvimento comunitário, no âmbito do património construído e quais são as representações relativas à participação dos moradores que deles emergem. A questão torna-se aqui ainda mais relevante, pois o Gabinete, que integra os técnicos camarários que aprovaram o projecto sem consulta pública e em confronto com os quais o movimento de moradores se encontra, foi estabelecido no Bairro Alto com o propósito claro de estar mais perto dos seus moradores, respondendo às suas necessidades e fomentando maior envolvimento comunitário. Estes objectivos vêm na sequência dos acordos saídos da Agenda 21 e do Tratado de Aalborg, que insistem na importância, para a sustentabilidade do desenvolvimento urbano, da participação dos cidadãos nos processos de tomada de decisão das suas comunidades, e estão estabelecidos nas legislações europeia e nacional.

Neste sentido, a controvérsia em torno da transformação do Convento está a ocorrer num contexto de mudança societal, no qual as alterações estão a ser impostas de cima para baixo - isto é, da legislação para as práticas, ou das normas para os factos. Assim, o nosso primeiro objectivo neste estudo será o de tentar compreender como é que, neste contexto de mudança imposta, em que a participação do público tem legitimidade ao nível das normas, mas dificuldade de atingir o nível das práticas, surgem diferentes formas de entender o que é a participação, com diferente valor social e diferentes níveis de aceitação.

Um segundo objectivo consiste em, numa abordagem psicossocial desta questão, articular os processos de nível macro, relativos à mudança social, com os processos de nível micro, relacionados com a comunicação e o discurso. Para esta articulação, levaremos em conta como é que o discurso concreto dos indivíduos em contextos específicos utiliza e adapta os recursos interpretativos partilhados, a que podemos chamar de representações sociais, a fim de respeitar os imperativos normativos que lhes estão a ser impostos, resistindo-lhes em simultâneo. Neste sentido, a controvérsia relativa ao Convento dos Inglesinhos é um caso particular a decorrer num bairro 
específico, mas que pode ser informativo das problemáticas que surgem na relação entre os sistemas técnico e leigo, num contexto em que a participação pública é uma norma ${ }^{3}$ legislada que vem impor a mudança nestas relações.

Para dar conta destes objectivos, o presente texto irá primeiro apresentar algumas das questões que se levantam em torno do facto de haver mudanças sociais impostas de forma normativa, bem como abordar alguns assuntos relacionados com as consequências da diversidade de ideias e identidades nas nossas sociedades. O objectivo destas primeiras páginas é expor com algum detalhe o conjunto de instrumentos analíticos com que iremos posteriormente interpretar o material recolhido, nomeadamente as entrevistas aos técnicos.

\section{Esfera pública e representações sociais}

Uma das abordagens que tem salientado a importância da reflexão sobre a dinâmica da produção, apropriação, estabilização e transformação das ideias (Moscovici, 1981; Turner, 2005) e sobre a interacção destas com as instituições das sociedades, para se entender como decorre a mudança ao nível das mentalidades e representações de uma sociedade, é a Teoria das Representações Sociais, mostrando que os indivíduos estão continuamente envolvidos nas actividades simultâneas de re-produção e de transformação das representações sociais (Moscovici, 1981). Esta ideia de uma "sociedade pensante", articulada com a dimensão da "sociedade argumentativa" acrescentada por Billig (Billig, Condor, Edwards, Gane, Middleton \& Radley, 1988), acentua o carácter heterogéneo da esfera pública das sociedades actuais, que integra não só uma grande variedade de "comunidades interpretativas" (Habermas, 1998), como também uma grande variedade de posições identitárias que estão abertas a cada indivíduo (Turner, Hogg, Oakes, Reicher \& Wetherell, 1987), podendo ser ocupadas em diferentes contextos e alturas, de acordo com diferentes objectivos.

É, portanto, através da participação na esfera pública - através da discussão nos media, da criação de blogs, jantares, etc. - que os grupos e os indivíduos, com diferentes discursos e posições, estabelecem e negoceiam e transformam significados, identidades e representações, actualizando e moldando o senso comum (Moscovici, 1981; Jovchelovitch, 2002). Contudo,

\footnotetext{
${ }^{3}$ Entendemos por norma referenciais com desejabilidade social impostos aos indivíduos por via da organização da sociedade, distinguindo, assim, este conceito do de representação social. Neste sentido, o sistema normativo - composto por normas sociais - regula as representações sociais e o sistema cognitivo opera com elas (Moscovici, 1976; Vala, 2000).
} 
este potencial dialógico da esfera pública (Habermas, 1989) tem limites précisos, uma vez que os debates são sempre constrangidos pelos diferenciais de poder material e simbólico entre os que nele participam (Campbell \& Jovchelovitch, 2000), pois estes estão posicionados numa hierarquia definida por aspectos estruturais e ideológicos imputadores de diferente valor social às identidades e às representações que circulam na esfera pública (ver Fiske, Cuddy, Glick \& Xu, 2002, para uma ilustração abrangente; Amâncio, 2003; Deschamps, 2003). Esta diversidade dos tipos - e não apenas dos conteúdos - das representações, bem como as diferenças relativamente ao consenso que suscitam, é claramente identificada na distinção entre représentações hegemónicas, emancipadas e polémicas (Moscovici, 1988). Esta pretende dar conta do potencial de inovação das representações sociais, que se podem transformar no debate e na argumentação, em particular quando são polémicas, acentuando o seu papel na mudança social (Castro, 2002).

Outra proposta que dá conta desta diversidade é a distinção entre representações transcendentes e imanentes (Harré, 1998), ou seja, entre representações que existem independentemente das práticas - penetrando na sociedade por via de normas ou imperativos; e representações que só existem por referência à prática para que são relevantes - surgindo de práticas já enraizadas, referentes geralmente a representações mais antigas (Jodelet, 1989).

Contudo, a introdução de novas representações no senso comum de uma sociedade não significa que o sistema representacional já existente mude de forma súbita, desfazendo-se da antiga e aceitando a nova (Castro \& Lima, 2001). Pelo contrário, e durante um período de tempo que pode ser bastante longo, "a mudança resulta na coexistência simultânea de representações concorrentes (com frequência, logicamente incompatíveis, mas socialmente aceitáveis), embuídas em discursos diferentes" (Wagner \& Hayes, 2005, p. 232). Esta ideia, que acentua o carácter dialógico das representações sociais, foi demonstrada em vários estudos conduzidos com recurso à noção de polifasia cognitiva (Moscovici, 1976; Jovchelovitch \& Gervais, 1999; Wagner, Duveen, Verma \& Themel, 1999). Esta noção, que se refere a um "estado em que diferentes tipos de conhecimento, possuindo diferentes racionalidades, vivem lado a lado no mesmo indivíduo ou colectivo" (Jovchelovitch, 2002, p. 124), permitiu, através destes estudos, concluir que, em situação de mudança, os campos representacionais são híbridos, compósitos e ambivalentes (Castro \& Lima, 2001). Permitiu ainda salientar que a coexistência de representações contraditórias tem um carácter instrumental de adaptação do discurso e prática do grupo a uma realidade cada vez mais variada e paradoxal (Wagner et al., 1999).

Uma outra proposta, que foi introduzida pela abordagem estrutural das Representações Sociais (Guimelli, 1998) e recentemente desenvolvida 
de forma a examinar esta instrumentalidade no contexto da expressão intra-individual de ideias contraditórias, distingue entre a função normativa e funcional das representações. Utilizando esta distinção, Moloney \& Walker (2002) verificaram que o campo representacional da doação de órgãos pode ser visto como compreendendo duas perspectivas conflituosas: uma perspectiva pró-doação, baseada nos benefícios da doação para a sociedade, que emerge se a doação estiver a ser discutida não fazendo referência directa ao indivíduo e que corresponde à dimensão normativa; e outra perspectiva baseada nos perigos para o indivíduo, associados com a remoção de partes do corpo, que emerge quando se discute o que o indivíduo faria se estivesse ele próprio nessa situação - dimensão funcional. Na dinâmica do pensamento social, o facto de este operar com base em campos representacionais híbridos permite a coexistência de objectivos normativos com crenças que, na prática, funcionam como resistência a estes.

Uma outra forma de lidar com representações contraditórias na argumentação é através do uso da particularização, ou a criação de "casos especiais", vistos como excepções a uma categoria (Billig, 1985), que permitem contornar aquilo que é normativo, sem se opor a ele.

Concluindo, e de acordo com estes estudos, a coexistência de representações divergentes tem um papel instrumental na adaptação do discurso e práticas do grupo à mudança social e aos diferentes contextos das suas vidas. Estes contextos podem ser entendidos de duas formas - tanto como o contexto próximo da comunicação interpessoal concreta que está a ter lugar, como o contexto distante, que inclui a hierarquia de ideais valorizadas socialmente e posições identitárias.

\section{Participação pública como norma}

Nos últimos anos, várias vozes se levantaram para defender a necessidade de tornar mais transparentes os processos de tomada de decisão que envolvem saberes técnico-científicos (Campbell \& Jovchelovich, 2000; Castro \& Lima, 2003; Lima, 2004). Vários autores (Beck, 1998; Wynne, 1996) teorizaram e ilustraram a forma como, na actualidade, os saberes técnico-científicos tendem a tornar-se impermeáveis à "fiscalização" da esfera pública, produzindo sobre as suas decisões uma opacidade que não se pode considerar democrática, e afirmaram a necessidade de tornar as relações entre os sistemas técnico e leigo mais transparentes (Gonçalves, 2000) e de encarar os públicos como fontes de conhecimento que deve ser integrado nos processos de decisão que os afectam.

Também o debate social inaugurado a partir dos anos 70 sobre questões de sustentabilidade ambiental e a produção legislativa que se seguiu 
(Agenda 21, Tratado de Aalborg) contribuíram fortemente nesta direcção, afirmando a participação local como uma via indispensável para a sustentabilidade, quer em relação ao ambiente natural (Bonnes \& Bonaiuto, 2002), quer ao ambiente construído (Pol, 2002). A participação pode, no entanto, atríbuir maior ou menor poder ao público, criando, assim, a distinção entre uma estratégia pedagógica da participação ou uma estratégia dialógica (Lima, Marques-Pinto, Castro \& Baptista, 2001; Lima, 2004). A primeira adopta uma perspectiva informativa e unilateral, ancorando-se na expertise técnica como forma de relação com o público e pretedendo, essencialmente, informá-lo (Castro \& Lima, 2003). Já a estratégia dialógica, a assumida na Agenda 21, considera que existem várias representações da realidade, acompanhadas de diferentes posições e objectivos, e que estas têm que ser tidas em conta e integradas na decisão, após debate aberto e multidireccional. Encarada desta forma mais dialógica, a participação local é apontada como garantia de constitutuição de uma sociedade vertebrada (Pol, 2002) e a melhor forma de lidar com os problemas sociais, económicos e ambientais das nossas "sociedades fragmentadas" (Horelli, 2002), ajudando a combater comportamentos anómicos desestruturantes e ameaçadores da sustentabilidade ambiental.

Também a legislação portuguesa consagra - em muitas áreas e em algumas delas na esteira das directivas europeias e da Agenda 21 - a informação e participação do público como parte integrante dos direitos dos cidadãos. A importância da participação pública é, assim, um valor hoje unanimemente afirmado na União Europeia e também na sociedade portuguesa. No entanto, são também frequentes as análises que reconhecem, no nosso país e em torno desta questão um fosso acentuado entre normas e factos (Santos, 2003; Lima, 2004), entre o que é pensado teoricamente para ser aplicado e o que depois é, de facto, aplicado.

Este fosso é precisamente o que pretendemos discutir neste trabalho. Quando existem ideias socialmente valorizadas e formalmente legisladas que têm um impacto fraco ao nível das práticas, uma forma claramente socio-psicológica de abordar esta dualidade é através da tentativa de ligar os macroprocessos gerais impulsionadores de mudança, com os microprocessos particulares envolvidos no significado concreto que as normas recebem, quando apropriadas e negociadas em casos específicos. Uma vez que estes significados concretos são mantidos, explicados e justificados através do discurso quotidiano e das representações que ele convoca, é necessário examinar este discurso, para compreender de que forma as representações se conjugam e se opõem e como se articulam com as identidades sócio-técnicas, particularmente em casos de controvérsia aberta, quando os dilemas e perspectivas contrárias envolvidos numa situação são claramente expostos (Billig et al., 1988). 
De uma forma mais específica, as questões que se colocam neste trabalho são, então, as seguintes: (1) nos debates entre a esfera pública e a esfera técnica, de que forma é que a argumentação se organiza para definir as questões de uma maneira que não viole o que deve ser, isto é, as normas, mas preserve a especificidade dos interesses e identidades próprias? Qual o papel da polifasia cognitiva na gestão desta relação? (2) qual é o papel que, na concretização discursiva, a esfera técnica atribui ao público - as competências alargadas que o modelo dialógico da participação indica, ou outras mais restritivas?

\section{Materiais e métodos de recolha de dados}

Com o intuito de compreender a controvérsia relativa ao Convento, analisou-se a imprensa, tendo sido, durante o período de Agosto a Dezembro de 2004, recolhidos, em quatro jornais diários, 13 artigos que discutiam esta questão. Assistimos também a duas sessões públicas promovidas pelo movimento de moradores, onde os vários interesses e perspectivas, à excepção do proprietário da construção, estavam representados. A análise da imprensa e as notas tiradas nestas sessões ajudaram a reconstruir o contexto representacional da controvérsia.

Numa segunda etapa, realizámos seis entrevistas narrativas, uma metodologia frequentemente adoptada pela perspectiva dialógica da Teoria das Representações Sociais (Jovchelovitch \& Gervais, 1999; Markova, 2003). As entrevistas focaram-se na narração do processo, como uma estória a decorrer no tempo, procurando entender o funcionamento da polifasia cognitiva, relativamente ao entendimento dos técnicos do Gabinete sobre a participação pública, a partir desta controvérsia em particular.

Assim, realizámos cinco entrevistas com os técnicos do Gabinete do Bairro Alto - um de cada categoria profissional - e a sexta com o porta-voz do movimento de moradores. As entrevistas, que tiveram uma duração média de $1 \mathrm{~h} 30 \mathrm{~m}$, foram apresentadas como tendo o objectivo de compreender as várias etapas e grupos intervenientes envolvidos na controvérsia dos Inglesinhos. Contudo, e uma vez que sabíamos de antemão que também pretendíamos ouvir os entrevistados falarem sobre a participação pública em geral, e não apenas em relação àquele caso específico, sempre que estes não expressavam espontaneamente as suas perspectivas sobre essa questão, nós perguntávamos explicitamente. As perguntas, no entanto, não foram feitas de uma forma rígida e foi possível manter um contexto informal nas entrevistas. 


\section{O contexto da controvérsia}

Partindo da informação reunida na imprensa, nas entrevistas e nas notas recolhidas por nós nas sessões públicas, iremos agora reconstruir o contexto representacional da controvérsia.

O movimento de moradores, encabeçado por intelectuais conhecidos da sociedade portuguesa, é o grupo melhor representado na imprensa, como defensor da conservação integral dos Inglesinhos, sendo as transformações previstas no Convento - um "local onde se "respira" história" (Público, 23.09.2004) - vistas por este grupo como uma "descaracterização do Bairro que urge travar" (Diário de Notícias, 8.10.2004) e algo a que os moradores, a quem deve ser dado o direito de participarem activamente na gestão urbanística, se opõem.

Também representada na imprensa, ainda que sem tanta força de expressão, é a opinião de outros moradores, partilhada pelos representantes da Junta de Freguesia, que assinalam que, apesar de considerarem importante a preservação histórica do Bairro, se preocupam também com a sua sustentabilidade económica, considerando, assim, que, "desde que seja garantida a preservação do património, é preferivel ter ali o que vamos ter do que aquilo que lá estava" (Público, 29.10.2004). Assim, este outro grupo "dará o seu aval caso a igreja "seja preservada e acessivel à população" (Público, 21.11.2004).

Por sua vez, os técnicos camarários - historiadores, arquitectos, sociólogos e juristas -, ligados ao Gabinete responsável pelo Bairro Alto, consideram que o projecto actual para o condomínio de luxo que vai ser construído é positivo para a reabilitação urbana do bairro, na medida em que dá um novo uso ao espaço, mantendo os seus elementos patrimoniais mais significativos: "preserva as características fundamentais (históricas e arquitectónicas) das construções existentes" (Diário de Notícias, 8.10.2004). Por este motivo, para os técnicos, o movimento de moradores não faz sentido: "alguns moradores da zona insistem (...) na necessidade da salvação dos Inglesinhos como se esta não estivesse plenamente assegurada desde o final de 2002" (in carta publicada no Público, 2.12.2004).

A leitura da imprensa e a assistência às reuniões de moradores indicavam, então, que o papel dos técnicos da Unidade de Projecto do Bairro Alto e Bica, gabinete camarário cujas principais funções são a preservação e reabilitação do Bairro Alto e o acompanhamento dos seus moradores, era central e deveria ser examinado em detalhe, para melhor se compreender as concepções sobre a participação do público emergentes do confronto entre os sistemas sócio-tecnicos e leigos e se perceber como é que eram geridas, na prática, pelo sistema técnico as exigências contraditórias entre aceitar a participação, dado o carácter normativo desta, e resisitir a incorporar as suas propostas. 


\section{Análise das entrevistas: a participação pública entre normas e factos}

Para concentrarmos as análises da entrevista sobre a questão da polifasia cognitiva relativamente à participação pública, procedemos da seguinte forma: em primeiro lugar, lemos as entrevistas na íntegra e seleccionámos os excertos que se referiam à participação pública e às opiniões face a esta controvérsia e ao Convento; de seguida, contrastámos as diferentes formas que os entrevistados usavam para discutir estes assuntos. Assim, foi possível concluir que as entrevistas dos técnicos do Gabinete apresentam uma organização discursiva estruturada na dicotomia entre (1) a defesa em geral - da participação dos moradores e dos cidadãos nas questões das suas cidades e (2) a desqualificação da legitimidade do processo - em concreto - que está em curso no Bairro. Ou seja, quando estão a referir-se à participação dos moradores naquele caso concreto, os técnicos da reabilitação urbana do Gabinete desqualificam os objectivos e acção dos moradores. No entanto, questionados em relação à participação pública de uma forma geral, argumentam a favor da participação e do direito ao exercício da cidadania, não só como importantes na defesa do património, mas como cumprimento do ser cidadão:

“... Relativamente ao facto de ter havido esta movimentação, isso em si eu acho extremamente positivo, porque não é todos os dias infelizmente que eu acho que as pessoas deviam de facto intervir muito mais a esse nível, (...) para tentar protestar contra aquilo que lhes parece que não é correcto, $\mathbf{e}$ isso eu acho muito, muito positivo" [AF, Socióloga, p. 3].

Este extracto mostra como o envolvimento do público é qualificado de positivo. Contudo, as frases que se seguem revelam que as motivações que estão na base deste movimento não são consideradas tão positivas:

"Agora que me parece que há algum cuidado e se calhar há algumas [questões] mais particulares que não se prendem directamente com a salvaguarda do património em termos mais estritos, também penso que sim. Portanto, há pessoas que se sentem mais directamente lesadas pela intervemção que vai ser feita ali, e portanto têm um papel preponderante nesse movimento e enfim. (...) não conheço muito bem as pessoas do, desse grupo, portanto sei que algumas moram na área e portanto estão directamente interessadas, ou porque vêem o edifício ou porque, enfim de alguma forma a intervenção que vai ali ser feita vai condicionar ou não depois o seu dia-a-dia (...) portanto estarão mais preocupadas com essa vertente..." [AF, p. 4].

Esta dupla argumentação remete-nos claramente para o mecanismo de particularização apontado por Billig (1985), uma vez que os técnicos do 
Gabinete extraem este caso particular da categoria de participação pública, justificando-o como sendo apenas a defesa de interesses particulares e não a defesa do património e, portanto, como não sendo verdadeiramente participação pública.

\section{Técnicos ou cidadãos: eis a questão}

Uma outra forma que os técnicos do Gabinete utilizam para lidar com o dilema em que se encontram é o que podemos chamar de "alternância identitária". Quando olham para esta questão através da sua identidade profissional, enquanto técnicos, os entrevistados particularizam este caso e ilegitimam-no dentro do enquadramento da participação pública. Mas quando, noutras alturas da entrevista, falam acerca da participação pública no geral, enquanto direito de cidadania, adoptam a identidade de cidadãos e defendem a participação, incentivando-a:

“... sou $100 \%$ a favor que os grupos de cidadãos, que a sociedade civil tenha uma voz activa neste, nestas questões da cidade, fundamental. $\underline{\mathrm{Eu}}$ próprio colaboro com uma amiga minha que mora nesse sítio, noutras lutas, noutras organizações de cidadãos em defesa daquilo que se considera válido para as zonas onde se habita, portanto acho tremendamente válido" [AM, Historiador, pp. 23-35].

Neste extracto, vemos que a participação pública é defendida como um direito de cidadania a que recorre o próprio técnico, que aqui utiliza o pronome pessoal "eu" para se referir a si enquanto cidadão. Há aqui a convergência entre os interesses do self e os interesses da sociedade, participando tanto um como o outro do imperativo normativo referente à participação pública, enquanto representação hegemónica. Contudo, a partir do momento em que se começam a referir ao caso particular dos Inglesinhos, os entrevistados assumem a sua identidade de técnicos e passam a utilizar no discurso a oposição "Nós" e "Eles" para falarem sobre esta questão, colocando-a num contexto de conflito inter-grupal, que reflecte a polemização da representação de participação quando esta é discutida a partir das práticas que os envolvem:

"Mas que efectivamente a nós nos incomoda que a contestação só surja quando começam as movimentações de trabalhos, também nos incomoda (...) Portanto, [eles] só estão preocupados com o património quando [eles] começam a ser incomodados por causa de obras?" [AM, pp. 8-9].

Também na entrevista a um outro arquitecto do Gabinete a mesma alternância identitária cidadão/técnico é aparente:

“... porque quem melhor defende os seus problemas do que aqueles que os sentem? Que os vivem dia-a-dia? (...) Porque eu também estou do outro 
lado, também sou cidadão. E sei também que um dia posso lá estar daquele lado, e sei que as pessoas têm sempre o direito a reclamar, e à indignação e recorrer das situações (...).(...) as pessoas têm o direito, eu acho que é uma liberdade que é assim, acho que é importante as pessoas manifestarem-se nestes movimentos (...) independentemente se têm ou não razão" [VC, Arquitecto Paisagista, pp. 22-24].

$\mathrm{Na}$ esfera abstracta da cidadania, técnicos e moradores pertencem ao mesmo grupo, como elementos intermutáveis de uma mesma categoria. Contudo, quando falam sobre a controvérsia, adoptam a sua identidade técnica e falam a partir dela sobre este caso como não sendo participação pública:

“... mas depois, de vez em quando, aparecem uns arautos, quer dizer, açordam de repente, emergem das tumbas e dizem que realmente são os defensores do património e tal, mas antes eles estavam lá e não apareceram nem aqui nem acolá, só porque são vizinhos daquilo é património importante. Isto portanto, a lógica da opinião pública é uma coisa muito estranha e nada coerente" [VC, pp. 3-4].

É na encruzilhada entre os dois tipos de posições que acabámos de apresentar que toma sentido falar de uma dualidade/contradição que é permitida pelo facto de ambas as posições serem sustentadas por argumentos que as justificam e que fazem sentido, quando vistos de forma isolada. Por isso, esta contradição entre o que se diz enquanto técnico e o que se afirma enquanto cidadão nos remete para o conceito de polifasia cognitiva (Moscovici, 1976; Jovchelovitch \& Gervais, 1999; Wagner et al., 1999), na medida em que estes técnicos se apoiam em duas representações distintas sobre a questão dos Inglesinhos, ancoradas em duas identidades diferentes. Aqui apercebemo-nos também das dimensões normativa e funcional (Moloney \& Walker, 2002). A dimensão normativa é adoptada quando os técnicos do Gabinete falam da participação pública, de uma forma geral, uma forma distante da sua prática enquanto profissionais. Nesta esfera abstracta, também eles são cidadãos e podem vir a necessitar de mobilizar um dia o imperativo normativo da participação pública. Contudo, quando estão a falar sobre os Inglesinhos, ou seja, num contexto próximo e que os implica directamente enquanto profissionais, é na dimensão funcional que constroem o seu discurso, desqualificando os moradores nos seus objectivos.

\section{Quem se interessa pela participação pública?}

Um outro aspecto passível de análise nestas entrevistas é a forma como estes técnicos olham para o papel dos moradores e dos cidadãos na participação pública. Ao mesmo tempo que consideram a necessidade de os cidadãos se envolveram nas questões da cidade e da sua preservação, apon- 
tam a falta de interesse destes em relação a esta questão. Ao longo das entrevistas, os entrevistados enumeram alguns casos que têm o self como protagonista, na tentativa de envolver os públicos em decisões das suas comunidades, argumentando depois que estes não se interessaram, não participaram, não perguntaram:

“... andámos pela rua a distribuir e a conversar com as pessoas para termos uma ideia de como é que as pessoas aceitariam a ideia de... em vez de impor uma rua pedonal, queriámos saber como é que as pessoas reagiam à pedonização da rua, portanto, eu sou completamente adepto deste tipo de coisas (...) mas a população, a sério, foi deprimente... as pessoas a maior parte estava-se nas tintas, que é uma coisa que me mete confusão, é a tal falta de cultura, nós não temos de facto uma cultura de cidadania em que as pessoas se sintam elas próprias como parte integrante de um sistema em que elas também têm uma palavra a dizer" [AM, pp. 35-36]

Como vemos, é o público que é retratado como desinteressado e não se envolvendo: é, por isso, culpado de não haver mais participação, uma vez que a esfera das possibilidades normativas está aberta (o Gabinete está ali, os técnicos também, estes até já estiveram envolvidos em alguma acções inclusivas da participação das populações), e as pessoas não a usam.

Este exemplo é claro quanto às questões que emergem do facto de haver necessidade de traduzir as regras e normas gerais para o seu contexto concreto de implementação: apesar de o Gabinete se ter deslocado para o Bairro com o intuito de estar mais perto dos seus moradores, há ainda que traduzir, no concreto, esta expressão. Assim, "mais perto dos moradores" pode querer dizer que devem ser estes a ir ter com o gabinete e fazer perguntas e demonstrar o seu interesse - concepção pedagógica da participação. Ou, pelo contrário, pode querer dizer que são os técnicos que devem activamente promover o debate e abrir canais de comunicação para incorporar as propostas e perspectivas dos moradores - concepção dialógica da participação. Destas entrevistas, emerge a ideia de que deverão ser os moradores a vir colocar questões e emerge, assim, uma concepção da participação como sendo, sobretudo, pedagógica:

"Entrevistadora - Mas e acha que essa cultura cívica deve ser criada, deve ser trabalhada, partindo dos moradores, ou partindo de iniciativas da Câmara, por exemplo, de aproximação?

$\mathrm{VC}-\mathrm{Eu}$ acho que, eu pessoalmente, e falando como cidadão, eu acho que deve partir dos moradores. Porque eles é que são a parte interessada" [VC, p. 7].

Por sua vez, o porta-voz dos moradores tem a perspectiva contrária, é o gabinete que deve promover debates públicos, aproximando-se dos cidadãos: 
“... Não houve nenhuma discussão pública por parte das instituições que deviam tê-la promovido com os habitantes daquela área. (...) Gabinete do Bairro Alto, nunca promoveram qualquer espécie de discussão pública, ou seja, com os habitantes da zona, acerca de qualquer coisa que ali estivesse para ser construída. (...) aliás os senhores do Gabinete do Bairro Alto, da tal Unidade de Projecto, têm o descaramento (...) para nos acusar de termos despertado tarde, quer dizer, nunca é tarde para despertarmos para estas coisas. Com certeza que despertámos tarde, mais acusavam-nos a nós de nunca termos ido falar com eles e eu respondi-lhe, sabe muito bem que quando Maomé não vai à montanha, vem a montanha a Maomé, vocês é que tinham a obrigação de vir falar connosco, coisa que nunca fizeram" [FC, Porta-voz dos moradores, p. 5].

Esta perspectiva pedagógica da participação pública implica, assim, que o público seja visto como necessitando sobretudo de informação (Castro \& Lima, 2003). Se os moradores se dirigissem ao Gabinete para se informarem do que se passa, seriam de imediato esclarecidos pelos técnicos e deixariam de olhar para os Inglesinhos como um problema, pois, confrontados com a expertise técnica sobre este assunto, compreenderiam o projecto e os objectivos dos técnicos. Assim, os técnicos diagnosticam o público como "enviesado" (Lima, 2004), pois este baseia a sua posição contra a transformação dos Inglesinhos em argumentos que não são válidos, levando-o a cometer erros de percepção quanto aos problemas que corre com este projecto, e que são sustentados pela sua falta de informação. Um destes argumentos/erros relaciona-se com o jardim que faz parte do Convento dos Inglesinhos e que, para o movimento de moradores, é visto como um jardim que importa preservar:

“... a parte por onde se entra dá sobre o jardim do Convento dos Inglesinhos, que é um belíssimo jardim. Ora bem, é nesse belíssimo jardim que eles se preparam para perpetrar aquilo que eu considero como um verdadeiro crime, a vários títulos, patrimonial, ecológico ou ambiental, como você préferir, e que revela uma enorme falta de sensibilidade, por parte das pessoas que acham bem que se deite abaixo árvores de grande porte, árvores centenárias" [FC, pp. 1-2].

Já os técnicos do Gabinete minimizam completamente a importância deste jardim, nem sequer o considerando verdadeiramente como tal:

“Isso é outro equívoco, não há jardim ali, há árvores plantadas, nuns canteirinhos feitos nos inícios do séc. $\mathrm{XX}$, as árvores não são centenárias, lhe garanto, isso também é outra coisa. (...) não é um jardim histórico no seu verdadeiro sentido e são uns canteirinhos miseráveis (...) mas assim é... quintalzinho ajardinado (...) é isso aí, é um matagal que aí está, não é jardim, percebe, no sentido de jardim (...) mas é só para vos falar da questão de como se pode manipular também a opinião pública a este nível (...) o 
que está em causa é um espaço aberto, verde, mas não jardim" [AM, pp. 14-15].

Parece, então, claro, a partir deste conjunto de divergências, que a lei genérica que diz respeito ao envolvimento do público tem que ser interpretada e implementada - e que isto são tudo oportunidades para que as divergências surjam. O debate que se segue à divergência, por sua vez, faz surgir diferentes justificações, e estas e as práticas que lhes subjazem são uma oportunidade de observar as representações imanentes do envolvimento do público, que existem independentemente das normas de participação (Harré, 1998). Neste sentido, a capacidade de manter, lado a lado, ideias e práticas, tanto novas como velhas, é assegurada pelo facto de podermos alternar de identidade e escolher de uma variedade de possibilidades, tanto no que diz respeito ao conteúdo das representações, como no que se refere aos mecanismos retóricos que formatam a sua comunicação.

\section{Discussão}

Neste estudo, verificámos que técnicos e moradores olham de forma divergente para a controvérsia sobre os Inglesinhos e que agir de acordo com cada posição - e agir é também utilizar o discurso como recurso material e simbólico - tem consequências para a definição do grupo e da sua identidade social, enquanto forma de legitimar a acção e a posição do grupo. Assim, para os técnicos do Gabinete, a participação pública é vista através da lente do técnico e da lente do cidadão, mobilizando estes no seu discurso a instrumentalidade adaptativa da polifasia cognitiva, em relação à participação pública. No seu discurso de cidadãos, a participação pública é um direito fundamental - dimensão normativa. Já no seu discurso como técnicos do Gabinete, o que está a acontecer não é considerado participação pública, pois este caso é particularizado através da afirmação de que os moradores se movem por interesses pessoais. Da mesma forma, no discurso enquanto técnicos, está explícito que a participação nem sequer seria necessária - porque o que havia de patrimonialmente importante no Colégio já está a ser preservado, graças à acção dos técnicos.

Um outro aspecto que pretendíamos analisar aqui é o papel que é atribuído aos cidadãos na participação pública. Como vimos, actualmente, é incentivada a relação dialógica entre sistemas técnico e leigo e a integração dos públicos como parceiros nas decisões que têm que ver com as suas comunidades. Contudo, esta mudança da concepção pedagógica da participação para a sua concepção dialógica não é encontrada nas entrevistas aqui analisadas. Para estes técnicos, a participação é, por um lado, informativa, baseada nas pessoas irem ao gabinete fazer perguntas, uma vez que as 
explicações dos técnicos servirão para as esclarecer. Por outro lado, participar é protestar, discordar, expressar uma opinião. A questão de integrar esta divergência de perspectivas nas decisões não é sequer abordada.

Assim sendo, este duplo posicionamento permite que os técnicos do Gabinete consigam gerir duas posições - por um lado, respeitam a legitimidade normativa da participação pública e, por outro, garantem os seus próprios objectivos enquanto técnicos urbanísticos, que vão, muitas vezes, contra a norma da participação. Desta forma, a participação pública é mantida como uma representação transcendente e não imanente. Ora, se os técnicos do Gabinete adoptam esta perspectiva de que quem não se interessa pela participação são os públicos, dificilmente promoverão a articulação real e concreta entre os conhecimentos e perspectivas de cidadãos e técnicos. Em contexto urbano, esta desarticulação é catalisadora de uma maior anomia social (McCulloch, 2003). Reforça, portanto, a "sociedade fragmentada" contra qual os imperativos da participação pública pretendem lutar, garantido a transparência e a articulação da relação entre os sistemas técnico e leigo, para que a sustentabilidade ambiental não seja apenas um conceito inócuo, e que possa, de facto, ser uma realidade, através de um planemento participado e colaborativo.

\section{Conclusões}

Neste estudo, partindo da constatação da heterogeneidade de ideias e identidades na esfera pública, tentámos, num primeiro momento, caracterizar o contexto representacional de uma controvérsia que envolve as esferas técnica e leiga, num debate relativo ao património construído de um bairro em Lisboa. As transformações planeadas para o Convento dos Inglesinhos emergiram como um objecto de debate social ancorado em diferentes representações do Bairro Alto. Enquanto que os técnicos do Gabinete apoiavam esta transformação, o movimento de moradores estava contra ela. Ao longo do debate acesso que se seguiu, esta oposição mostrou a interdependência entre representações e identidades, mostrando que os indivíduos "possuem vários formas de pensar e representar" e como "a polifasia cognitiva é inerente à vida mental, como a polissemia o é para a vida da linguagem", e é de "grande importância prática para a comunicação e a adaptação às necessidades de mudança social" (Moscovici, 1998, pp. 246-7; 2001).

Neste sentido, através deste estudo, conseguimos compreender melhor que mecanismos permitem a estes técnicos a gestão (e manutenção) da dicotomia normas e factos da participação pública. No futuro, pretendemos fazer o caminho inverso, ou seja, compreender como os moradores olham para a participação pública e percepcionam esta dicotomia. Contudo, e co- 
mo vimos, a cobertura pela imprensa desta controvérsia centrou-se neste movimento de moradores e, por isso, as opiniões e posições dos outros moradores não foram acedidas aqui. Assim, em estudos futuros, pretendemos "des-homogeneizar" as posições das pessoas do Bairro, analisando porque é que algumas pessoas estão mais envolvidas com a defesa do Convento e outras menos mobilizadas por esta questão, tentando compreender como é que estas posições podem estar ligadas à identidade de lugar e o que é que dá a noção de eficácia e empowerment a estes moradores e pode promover comunidades ambiental e socialmente preservadas e sustentáveis, apesar das dificuldades encontradas.

\section{Referências}

Amâncio, L. (2003). Género e assimetria simbólica: O lugar da História na psicologia social. In M. L. Lima, P. Castro \& M. Garrido (Orgs.), Temas e Debates em Psicologia Social (pp. 111-124). Lisboa: Livros Horizonte.

Beck, U. (1998). Politics of risk society. In J. Franklin (Ed.), The politics of risk society (pp. 9-22). Cambridge: Polity Press.

Billig, M. (1985). Prejudice, categorization and particularization: From a perceptual to a rethorical approach. European Journal of Social Psychology, 15 (1), 79-103 .

Billig, M., Condor, S., Edwards, D., Gane, M., Middleton, D. \& Radley, A. (1988). Ideological dilemmas: The social psychology of everyday thinking. London: Sage.

Bonnes, M. \& Bonaiuto, M. (2002). Environmental Psychology: from spatial-physical environment to sustainable development. In R. B. Bechtel \& A. Churchman (Orgs.), Handbook of Environmental Psychology (2nd ed., pp. 28-54). New York: John Wiley \& Sons.

Campbell, C. \& Jovchelovitch, S. (2000). Health, community and development: Towards a social psychology of participation. Journal of Community and Applied Social Psychology, 10, 255-270.

Castro, P. (2002). Notas para uma leitura da teoria das representações sociais em S. Moscovici. Análise Social, vol. XXXVII (164), 949-979.

Castro, P., \& Lima, L. (2001). Old and new ideas about the environment and science: an exploratory study. Environment and Behavior, 33, 400-423.

Castro, P. \& Lima, M. L. (2003). Discursos sobre a ciência num debate ambiental. In M. E. Gonçalves (Org.), Os Portugueses e a Ciência (pp. 115-155). Lisboa: Publicações Dom Quixote.

Deschamps, J-C. (2003). Identidades e relações de poder em contexto intergrupal. In M. L. Lima, P. Castro \& M. Garrido (Orgs.), Temas e Debates em Psicologia Social (pp. 57-72). Lisboa: Livros Horizonte. 
Fiske, S., Cuddy, A., Glick, P. \& Xu, J. (2002). A model of (often mixed) stereotype content: competence and warmth respectively follow from perceived status and competition. Journal of Personality and Social Psychology, 82 (6), 878-902.

Gonçalves, M. E. (2000). The importance of being European: The science and politics of BSE in Portugal. Science, Technology \& Human Values, 25 (4), 417-448.

Guimelli, C. (1998). Differentiation between the central core elements of social representations: Normative vs. functional elements. Swiss Journal of Psychology, 57 (4), 209-224.

Habermas, J. (1989). Toward a Rational Society. Cambridge: Polity Press.

Habermas, J. (1998). Between facts and norms: Contributions to a Discourse Theory of Law and Democracy. New Baskerville, EUA: Massachussetts Institute of Technology.

Harré, R. (1998). The epistemology of social representations. In U. Flick (Ed.), The psychology of the social (pp. 129-137). Cambridge: Cambridge University Press.

Horelli, L. (2002). A methodology of participatory planning. In R. B. Bechtel \& A. Churchman (Orgs.), Handbook of Environmental Psychology (2nd ed., pp. 607-628). New York: John Wiley \& Sons.

Jodelet, D. (1989). Folies et représentations sociales. Paris: PUF.

Jovchelovitch, S. (2002). Re-thinking the diversity of knowledge: Cognitive poliphasia, belief and representation. Psychologie \& Société: Représentations et Croyances, 5, Tome 3 (1), 121-138.

Jovchelovitch, S. \& Gervais, M.-C. (1999). Social representations of health and illness: the case of the Chinese community in England. Journal of Community and Applied Social Psychology, 9, 247-260.

Lima, M. L. (2004). Images of the public in the debates about risk: Consequences for participation. Portuguese Journal of Social Sciences, 2 (3), 149-163.

Lima, M. L., Marques-Pinto, A., Castro., P. \& Baptista, C. (2001). Informação, responsabilidade e participação dos cidadãos no domínio hídrico. Lisboa: Centro de Investigação e Intervenção Social, ISCTE.

Marková, I. (2003). Dialogicality and social representations - the dynamics of mind. Cambridge: Cambridge University Press.

McCulloch, A. (2003). An examination of social capital and social disorganisation in neighbourhoods in the British household panel study. Social Science \& Medicine, 56 (7), 1425-1438.

Moloney, G. \& Walker, I. (2002). Talking about transplants: Social representations and the dialectical, dilemmatic nature of organ donation and transplantation. British Journal of Social Psychology, 41, 299-320.

Moloney, G., Hall, R. \& Walker, I. (2005). Social representations and themata: The construction and functioning of social knowledge about donation and transplantation. British Journal of Social Psychology, 44, 415-441.

Moscovici, S. (1961/1976). La Psychanalyse, son image et son public. Paris: PUF. 
Moscovici, S. (1981). On social representations. In J. P. Forgas (Ed.), Social cognition: perspectives on everyday understanding (pp. 181-209). London: Academic Press.

Moscovici, S. (1988). Notes towards a description of social representations. European Journal of Social Psychology, 18, 211-250.

Moscovici, S. (1998). The history and actuality of social representations. In U. Flick (Ed.), The psychology of the social (pp. 209-247). Cambridge: Cambridge University Press.

Pol, E. (2002). The theoretical background of the City-Identity-Sustainability Network. Environment \& Behavior, 34 (1), 8-25.

Santos, B. (2003). Conhecimento prudente para uma vida decente: um discurso sobre a ciência revisitado. Porto: Edições Afrontamento.

Turner, J. (2005). Explaining the nature of power: A three-process theory. European Journal of Social Psychology, 35, 1-22.

Turner, J., Hogg, M., Oakes, P., Reicher, S. \& Wetherell, M. (1987). Rediscovering the social group: A self-categorisation theory. Oxford: Blackwell.

Vala, J. (2000). Representações sociais e psicologia social do conhecimento quotidiano. In J. Vala \& M. B. Monteiro (Coords.), Psicologia Social (4. ${ }^{\mathrm{a}}$ ed., pp. 457-502). Lisboa: Fundação Calouste Gulbenkian.

Wagner, W., Duveen, G., Verma, J. \& Themel, M. (1999). The modernization of tradition: thinking about madness in Patna, India. Culture \& Psychology, 5, 413-445.

Wagner, W. \& Hayes, N. (2005). Everyday Discourse and Common Sense: The Theory of Social Representations. Hampshire, England: Palgrave Macmillan.

Wynne, B. (1996). May the sheep safely graze? In A. Irwin \& B. Wynne (Eds.), Misunderstanding science? The public reconstruction of science and techno$\operatorname{logy}$ (pp. 172-190). Cambridge: Cambridge University Press. 